\title{
Improved crystal structure solution from powder diffraction data by the use of conformational information
}

Article

Published Version

Kabova, E. A., Cole, J. C., Korb, O., Williams, A. C. and Shankland, K. (2017) Improved crystal structure solution from powder diffraction data by the use of conformational information. Journal of Applied Crystallography, 50. pp. 14211427. ISSN 0021-8898 doi:

https://doi.org/10.1107/S1600576717012596 Available at https://centaur.reading.ac.uk/72697/

It is advisable to refer to the publisher's version if you intend to cite from the work. See Guidance on citing.

To link to this article DOI: http://dx.doi.org/10.1107/S1600576717012596

Publisher: Wiley

All outputs in CentAUR are protected by Intellectual Property Rights law, including copyright law. Copyright and IPR is retained by the creators or other copyright holders. Terms and conditions for use of this material are defined in the End User Agreement. 


\section{CentAUR}

Central Archive at the University of Reading

Reading's research outputs online 


\title{
Improved crystal structure solution from powder diffraction data by the use of conformational information
}

\author{
Elena A. Kabova, Jason C. Cole, Oliver Korb, Adrian C. Williams and \\ Kenneth Shankland
}

J. Appl. Cryst. (2017). 50, 1421-1427

\section{IUCr Journals CRYSTALLOGRAPHY JOURNALS ONLINE \\ Copyright (C) International Union of Crystallography \\ Author(s) of this paper may load this reprint on their own web site or institutional repository provided that this cover page is retained. Republication of this article or its storage in electronic databases other than as specified above is not permitted without prior permission in writing from the IUCr. \\ For further information see http://journals.iucr.org/services/authorrights.html}


JOURNAL OF

APPLIED

CRYSTALLOGRAPHY

ISSN 1600-5767

Received 10 July 2017

Accepted 1 September 2017

Edited by Th. Proffen, Oak Ridge National Laboratory, USA

Keywords: crystal structure determination; powder diffraction; simulated annealing; conformational information; crystal structure database.

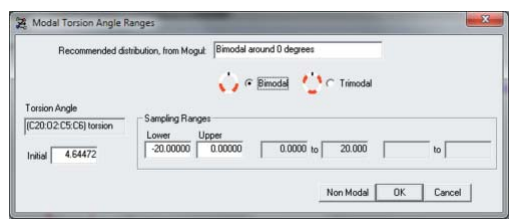

C 2017 International Union of Crystallography

\section{Improved crystal structure solution from powder diffraction data by the use of conformational information}

\author{
Elena A. Kabova, ${ }^{\text {a* Jason C. Cole, }}{ }^{\mathrm{b}}$ Oliver Korb, ${ }^{\mathrm{b}}$ Adrian C. Williams ${ }^{\mathrm{c}}$ and Kenneth \\ Shankland ${ }^{\mathrm{C}}$
}

\footnotetext{
${ }^{\mathbf{a}}$ School of Pharmacy, University of Reading, Whiteknights Campus, Reading, Berkshire RG6 6AD, UK, ${ }^{\mathbf{b}}$ Cambridge Crystallographic Data Centre, 12 Union Road, Cambridge, CB2 1EZ, UK, and ' ${ }^{\mathbf{S}}$ chool of Chemistry, Food and Pharmacy, University of Reading, Whiteknights, Reading, Berkshire RG6 6AP, UK. *Correspondence e-mail:

e.kabova@reading.ac.uk
}

The effect of introducing conformational information to the $D A S H$ implementation of crystal structure determination from powder diffraction data is investigated using 51 crystal structures, with the aim of allowing increasingly complex crystal structures to be solved more easily. The findings confirm that conformational information derived from the Cambridge Structural Database is indeed of value, considerably increasing the chances of obtaining a successful structure determination. Its routine use is therefore encouraged.

\section{Introduction}

Global optimization (GO)-based methods of crystal structure determination from powder diffraction data (SDPD) make explicit use of a significant amount of chemical knowledge; well characterized bond lengths and bond angles are typically held as fixed values throughout the optimization. Furthermore, certain torsion angles (such as those spanning a double bond) and certain components of molecules (for example, cyclic groups) are often treated as fixed entities. Any remaining torsion angles around which atoms are free to rotate are treated as variables to be determined by the GO procedure and are allowed to vary freely in the range of 0 $360^{\circ}$. Thus the conformational space of a molecule under study is treated as a continuum, rather than as a sequence of isolated conformations. This work sets out to improve the performance of SDPD by implementing conformational restraints or conformational bias, derived from observed crystal structures stored in the Cambridge Structural Database (CSD; Allen, 2002; Groom et al., 2016), to these freely varying torsion angles.

The utility of conformational information as constraints during crystal structure solution has long been recognized and has found particular application in macromolecular crystallography. For example, a protein molecule from a known crystal structure is often used as a start point for the crystal structure refinement of a distinct but closely related structure; see for example Scapin (2013) and DiMaio et al. (2011) and references therein. However, in the area of small-molecule crystallography, and in particular SDPD, conformational information has not been routinely employed, despite the fact that some work has demonstrated that it can be beneficial (CCDC, 2015; Florence et al., 2005; Middleton et al., 2002; Cole et al., 2014). Generally though, this evidence base is not strong, consisting of a few 'one-off' demonstrations and lacking 
Table 1

The 51 crystal structures used in this work.

\begin{tabular}{|c|c|c|c|}
\hline Code & Compound name & CSD refcode & Reference \\
\hline A7 & Zopiclone & CUHNEY10 & Borea et al. (1987) \\
\hline A16 & Tolbutamide & ZZZPUS02 & Donaldson et al. (1981) \\
\hline A18 & Pigment orange 36 (PO 36) & HOYVOH & van de Streek et al. (2009) \\
\hline A19 & $\left\{4^{\prime}-[2-(p\right.$-Tosylamino $)$ benzylideneamino $]-2,3$-benzo-15-crown-5\}-isothiocyanato-lithium & RIFVEI & Dorokhov et al. (2007) \\
\hline A 20 & Famotidine & FOGVIG03 & Florence et al. (2003) \\
\hline A 21 & Sotalol hydrochloride & SOTALC & Gadret et al. (1976) \\
\hline $\mathrm{A} 22$ & Glipizide & SAXFED & Burley (2005) \\
\hline A 23 & Diltiazem hydrochloride & CEYHUJ01 & Kojicprodic et al. (1984) \\
\hline A 24 & Zopiclone dihydrate & UCUVET & Shankland et al. (2001) \\
\hline A 25 & Capsaicin & FABVAF01 & David et al. (1998) \\
\hline A26 & Pigment yellow (PY 181 polymorph $\beta$ ) & GITWUC & van de Streek et al. (2009) \\
\hline A28 & Sodium 4-[(E)-(4-hydroxyphenyl)diazenyl] benzene sulfonate dihydrate & YAYWUQ & Kennedy et al. (2001) \\
\hline A 30 & Carbamazepine:indomethacin $1: 1$ & LEZKEI & Majumder et al. (2013) \\
\hline A31 & 2-[3-(2-Phenylethoxy)propyl sulfonyl] ethyl benzoate & BIFREO & Florence et al. (2005) \\
\hline A32 & $S$-Ibuprofen & JEKNOC10 & Freer et al. (1993) \\
\hline A33 & Ampicillin trihydrate & AMPCIH01 & Burley et al. (2006) \\
\hline A34 & Verapamil hydrochloride & CURHOM & Carpy et al. (1985) \\
\hline A 35 & Amodiaquinium dichloride dihydrate & SENJIF & Llinàs et al., 2006) \\
\hline A36 & Nifedipine (polymorph C) & BICCIZ01 & Bortolotti et al. (2011) \\
\hline A 37 & $\begin{array}{l}N \text {-[2-(4-Hydroxy-2-oxo-2,3-dihydro-1,3-benzothiazol-7-yl)ethyl]-3-[2-(2-naphthalen-1- } \\
\text { ylethoxy)ethylsulfonyl]propylaminium benzoate }\end{array}$ & PAHFIO & Johnston et al. (2004) \\
\hline A39 & Cyheptamide & TEVSOD01 & Florence et al. (2008) \\
\hline A40 & Ornidazole & NETRUZ & Shin et al. (1995) \\
\hline B21 & $\operatorname{Bis}\left\{4^{\prime}-\left[2-\left(p\right.\right.\right.$-tosylamino)benzylideneamino]-2,3-benzo-15-crown-5- $\left.N, N^{\prime}, O\right\} \operatorname{copper}(\mathrm{II})$ & RIFVAE & Dorokhov et al. (2007) \\
\hline $\mathrm{B} 27$ & 4-(Phenyldiazenyl)naphthalen-1-amine hydrochloride & QIJCAN & Yatsenko et al. (2001) \\
\hline B31 & Telmisartan (polymorph A) & XUYHOO01 & Dinnebier et al. (2000) \\
\hline B34 & Clarithromycin (polymorph I) & NAVSUY02 & Noguchi et al. (2012) \\
\hline B35 & Pigment orange 62(PO 62) & HOYVUN & van de Streek et al. (2009) \\
\hline B36 & Pigment yellow (PY 151) & HOYWAU & van de Streek et al. (2009) \\
\hline B37 & Pigment yellow (PY 154 polymorph $\alpha$ ) & HOYWEY & van de Streek et al. (2009) \\
\hline B38 & Pigment yellow 194 (PY 194) & HOYWIC & van de Streek et al. (2009) \\
\hline B39 & 2,4-Dinitro- $N$-phenyl-6-(phenylazo)benzamide & IHESUJ & Chernyshev et al. (2002) \\
\hline B40 & $N$-Methyl-2,4-dinitro- $N$-phenyl-6-(phenylazo)benzamide & IHETEU & Chernyshev et al. (2002) \\
\hline B42 & Trihexyphenidyl hydrochloride & KUZDIT & Maccaroni et al. (2010) \\
\hline B43 & $N$-(2-Methoxyphenyl)-2-(2-methoxyphenylazo)-4,6-dinitrobenzamide & IHETAQ & Chernyshev et al. (2002) \\
\hline B44 & Nimustine hydrochloride & WAWZAX & Bekö et al. (2012) \\
\hline B45 & $(R)$-1-Phenylethylammonium $(R)$-2-phenylbutyrate (polymorph II) & PBUPEA01 & Fernandes et al. $(2007 a)$ \\
\hline B46 & $(R)$-1-Phenylethylammonium $(R)$-2-phenylbutyrate (polymorph III) & PBUPEA02 & Fernandes et al. $(2007 b)$ \\
\hline B47 & Tetracaine hydrochloride & XISVOK & Nowell et al. (2002) \\
\hline B48 & $\alpha / \beta$-Lactose & LAKKEO & Lefebvre et al. (2005) \\
\hline B49 & $N$-(6-Phenylhexanoyl)glycyltryptophanamide & FEFNOV & Bushmarinov et al. (2012) \\
\hline B50 & Pigment yellow 183 (PY183 polymorph $\alpha$ ) & HOMMEC01 & Ivashevskaya et al. (2009) \\
\hline B51 & Pigment yellow 191 (PY191 polymorph $\alpha$ ) & HOMMIG01 & Ivashevskaya et al. (2009) \\
\hline B52 & Pigment yellow 191 (PY191 polymorph $\beta$ ) & HOMMOM01 & Ivashevskaya et al. (2009) \\
\hline B53 & Lisinopril dihydrate & GERWUX01 & Sorrenti et al. (2013) \\
\hline B54 & Prednisolone succinate & KIXDEB01 & Nishibori et al. (2008) \\
\hline B55 & Cytenamide (polymorph II) & SODNOP & Florence et al. (2008) \\
\hline B56 & Carvedilol dihydrogen phosphate propan-2-ol solvate & PUJTOE & Chernyshev et al. (2010) \\
\hline B57 & Ritonavir & YIGPIO01 & Bauer et al. (2001) \\
\hline B59 & D-Sorbitol & GLUCIT03 & Rukiah et al. (2004) \\
\hline B 60 & Chlorothiazide $N, N$-dimethylformamide solvate & NILSEH & Fernandes et al. (2007) \\
\hline B61 & $1,2,3,-$ Tris(nonadecanoyl)glycerol (polymorph $\beta$ ) & MEZNAG & Helmholdt et al. (2002) \\
\hline
\end{tabular}

detailed quantitative assessment of any performance gains achieved.

Of particular interest is the easily accessible ${ }^{\mathbf{1}}$ conforma- $^{-}$ tional information obtainable from the nearly 900000 crystal structures deposited in the CSD. All the tools necessary to search for, retrieve and analyse the structures from which relevant molecular geometry information can be derived are provided with the Cambridge Structural Database System (CSDS). With increasingly complex crystal structures being attempted by SDPD, it is therefore timely to re-visit the

\footnotetext{
${ }^{1}$ In the sense that there is no need to perform additional practical experiments, e.g. solid-state NMR.
}

potential of exploiting conformational information in a more systematic and wide-ranging study, to provide a definitive report of its benefits.

\section{Materials and methods}

2.1. Selection and composition of powder X-ray diffraction data sets

A recent publication (Kabova et al., 2017) described the optimization of the key simulated annealing (SA) parameters in DASH (David et al., 2006) using 101 crystal structures. All those structures for which a success rate of less than $60 \%$ was 
Table 2

Summary of software used in this work.

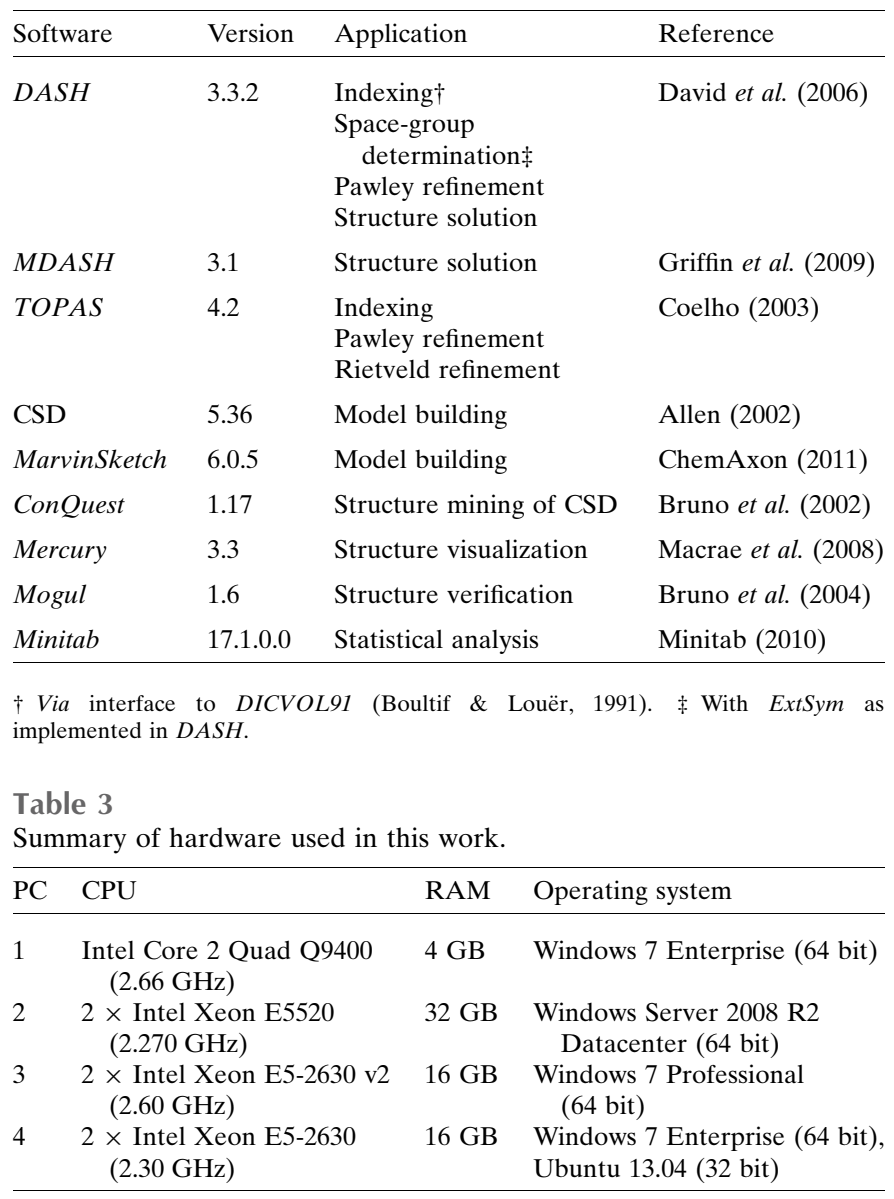

obtained in that work [using the default $D A S H$ SA parameters of cooling rate $(\mathrm{CR})=0.02, N_{1}=20$ and $\left.N_{2}=25\right]$ were selected for subsequent evaluation in this current work. Details of these 51 structures are given in Table 1.

\subsection{Software and hardware}

The software and hardware employed in this work are summarized in Tables 2 and 3.

2.2.1. Mogul. Mogul (Bruno et al., 2004) is a knowledgebased library of molecular geometries derived from the CSD. It acts as a source of information on preferred molecular geometries and as such can be used to validate the geometry of a solved structure. In the case of SDPD, our main interest is in obtaining information on preferred conformations of a molecule under study, based on the torsion angle distribution information contained in Mogul. $^{2}$ Taking the C6-C5-O2C20 torsion angle of verapamil hydrochloride (structure A34) as an example, the distribution of structurally closely related torsion angles (based on circa 11100 CSD-deposited crystal structures) is shown in Fig. 1. The distribution clearly shows that this torsion angle is likely to adopt a value in the range

\footnotetext{
${ }^{2}$ A full Mogul geometry check of any input molecular model constructed for GO-based SDPD is also highly recommended.
}
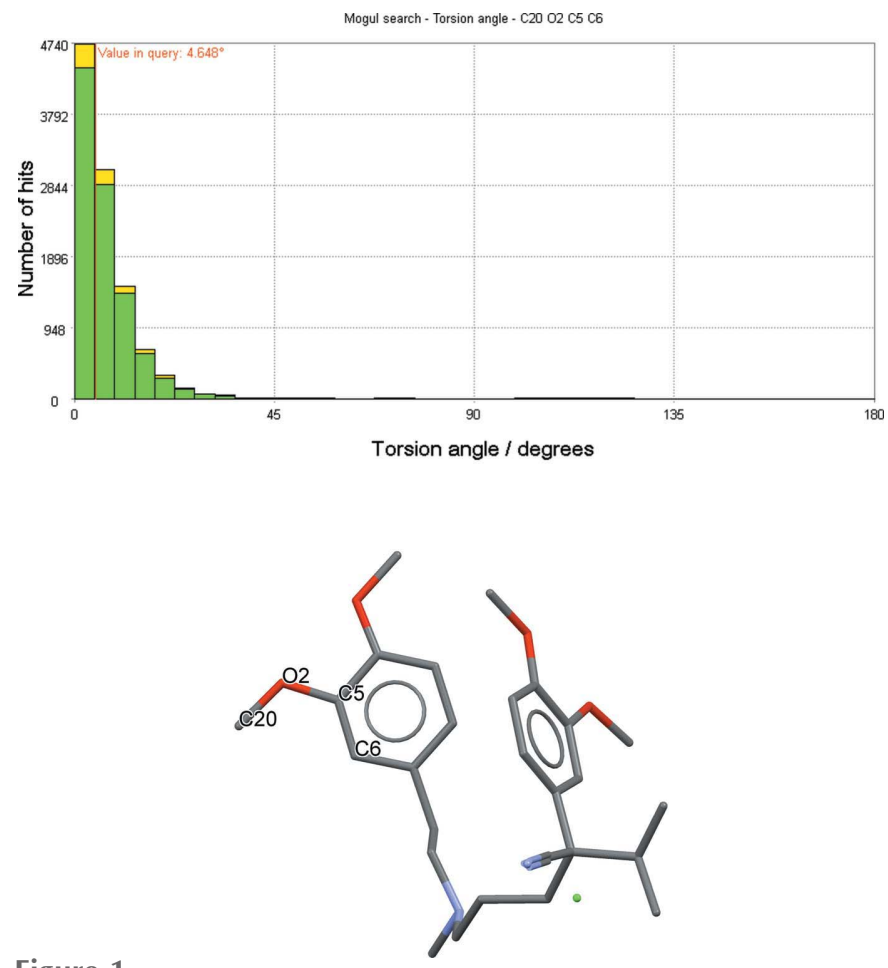

Figure 1

The Mogul-derived distribution (top) for the $\mathrm{C} 6-\mathrm{C} 5-\mathrm{O} 2-\mathrm{C} 20$ torsion angle of verapamil hydrochloride (A34, bottom).

$-20^{\circ}$ to $+20^{\circ}$, as approximately $95 \%$ of deposited crystal structures with this structural feature fall into this range.

2.2.2. Use of Mogul distributions as hard constraints within DASH. During the GO process, any torsion angle that is free to rotate in the molecule under study can be subjected to a Mogul query by pressing the 'Modal' button on the 'parameter bounds' window of $D A S H$ (Fig. 2). From the results of the Mogul query, a set of discrete constraints is derived. For example, in the case of the $\mathrm{C} 6-\mathrm{C} 5-\mathrm{O} 2-\mathrm{C} 20$ torsion angle of verapamil hydrochloride, only values in the ranges of $0^{\circ}$ to $+20^{\circ}$ and $-20^{\circ}$ to $0^{\circ}$ are permitted (Fig. 3 ). The reduction in search space from $360^{\circ}$ to only $40^{\circ}$ for one torsion angle is not expected to have a notable impact on the overall success rate

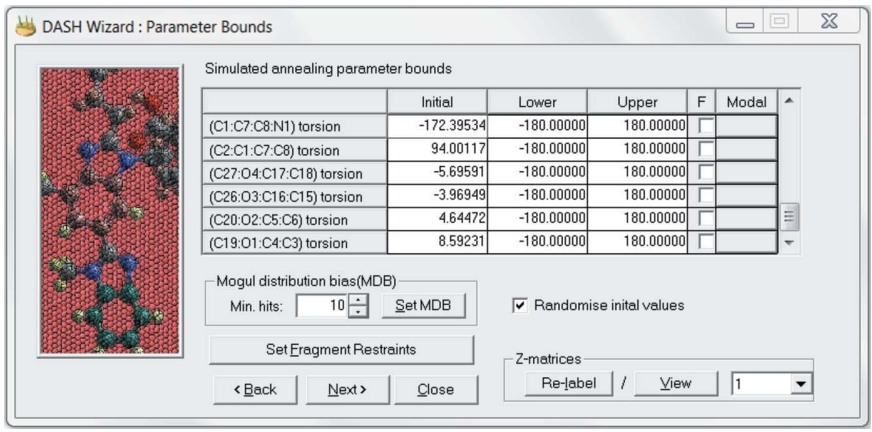

Figure 2

The 'parameter bounds' window of DASH. Mogul constraints are applied individually to each torsion angle in the form of modal distributions (see Fig. 3) using the 'Modal' option adjacent to each torsion angle description. In contrast, the MDB distributions are calculated automatically for all torsion angles when the 'Set MDB' button is pressed. 


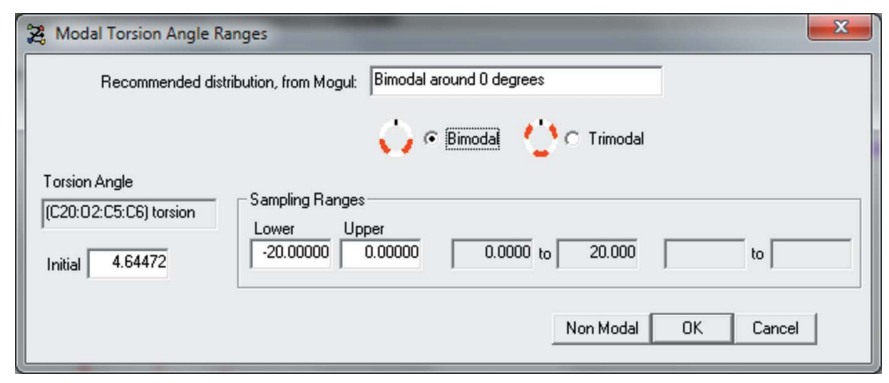

Figure 3

The modal ranges suggested for the $\mathrm{C} 6-\mathrm{C} 5-\mathrm{O} 2-\mathrm{C} 20$ torsion angle of verapamil hydrochloride (A34) based on the distribution shown in Fig. 1. Note that the user has the option to change the values of the ranges if desired. Note also that, for this particular torsion angle, the two ranges are adjacent and so effectively form a unimodal range spanning $-20^{\circ}$ to $+20^{\circ}$, restricting the methyl group to be either $20^{\circ}$ above or $20^{\circ}$ below the plane of the benzene ring.

in solving verapamil hydrochloride, but if similar Mogulderived restrictions are applied to all of the 14 variable torsion angles in the molecule, then the total search space reduction becomes more significant.

2.2.3. Use of Mogul distributions to bias parameter space sampling within DASH. Mogul distribution bias (MDB) is an alternative method of exploiting the Mogul-derived conformational information. In contrast to the Mogul-derived constraint approach, the MDB approach still samples the full 0-360 ${ }^{\circ}$ range for a torsion angle according to a Maxwellian distribution. However, here the Maxwellian is binned and multiplied by the value of the corresponding bin in the Mogul distribution, to generate a new distribution which favours moves to torsion angles in regions of space that are heavily populated in the Mogul distribution. MDB is invoked within $D A S H$ by pressing the 'Set MDB' button in the 'parameter bounds' window (Fig. 2). This automatically performs the necessary $\mathrm{Mogul}$ searches on all torsion angles that are free to rotate in the molecule under study. Considering again the $\mathrm{C} 6-\mathrm{C} 5-\mathrm{O} 2-\mathrm{C} 20$ torsion angle of verapamil hydrochloride, the Mogul search returns a string [hidden to the interactive user, but visible in the $D A S H$ batch file (DBF) that is generated for a batch run]: $4.6355 \mathrm{MDB}-1801801880722245$ 44611334189101091518281514161414 , where the initial torsion angle value $\mathbf{3}^{\mathbf{3}}$ is listed first, followed by the instruction to use the MDB approach, the minimum and maximum angular values, the number of bins in the probability histogram, and finally the number of observations in each bin.

The MDB and Mogul hard constraints approaches introduce the same underlying information in different ways, resulting in a different exploration of $\chi^{2}$ search space during the SA.

\subsection{Performance analysis}

An empirical log-of-the-odds (ELO) analysis was performed in order to evaluate any increase in the success rate

${ }^{3}$ This is the value of the torsion angle in the input model used by $D A S H$.
(SR) as a result of the conformational information introduced by the use of Mogul.

The ELO, described by Cox \& Snell (1989), can be written as

$$
\mathrm{ELO}=\ln \left(\frac{\mathrm{SR}_{i}+0.5}{100-\mathrm{SR}_{i}+0.5}\right)
$$

Logistic regression was performed using Minitab. Full details are given by Kabova et al. (2017).

\section{Experimental}

Following the protocol established previously, 50 SA runs were initially executed on all structures, using optimized SA control parameters of $\mathrm{CR}=0.27, N_{1}=73$ and $N_{2}=56$ (Kabova et al., 2017). Each run was set to perform $1 \times 10^{7} \mathrm{SA}$ moves followed by a short simplex calculation. A $\chi^{2}$ multiplier of 1 ensured the full number of SA steps was always carried out and the SA was not prematurely terminated. Five hundred SA runs of $5 \times 10^{7}$ moves were performed for compounds for which no successful solution was observed in the initial $100 \mathrm{SA}$ runs. The MDASH utility (Griffin et al., 2009) was used to distribute these longer runs over ten CPU cores. The option to manually alter any of the torsion angle ranges suggested by Mogul was not used. For consistency and to facilitate comparison of success rates, the same values of the random seeds in $D A S H$ were used throughout.

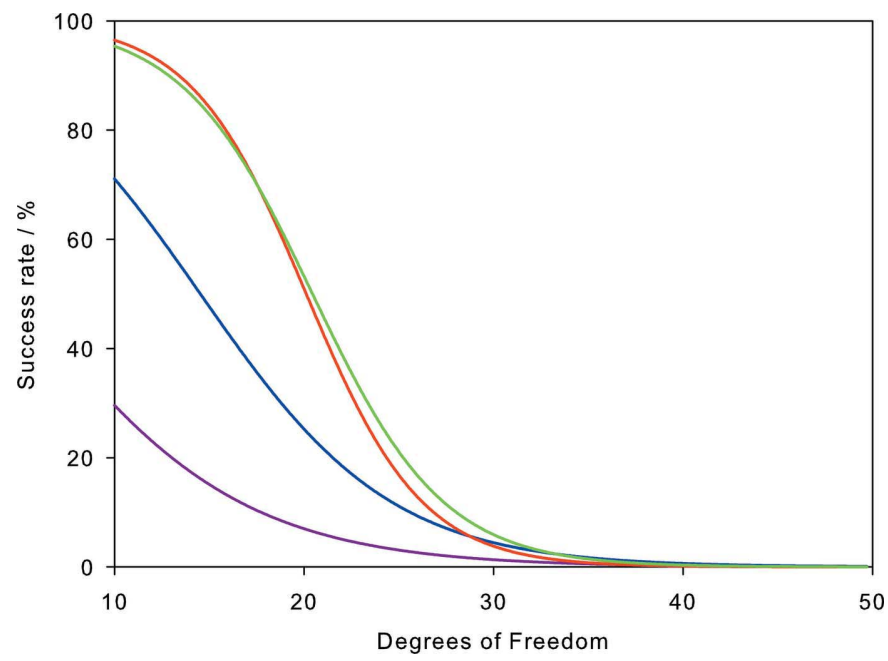

Figure 4

A comparison of the performance models based on the ELO regressions. The performance of the default $D A S H$ parameterization $\left(\mathrm{CR}=0.02, N_{1}=\right.$ $20, N_{2}=25$ ) with no conformational information is shown in purple, whilst the green line shows the performance of the best performing $D A S H$ parameterization $\left(\mathrm{CR}=0.27, N_{1}=73, N_{2}=56\right)$ with the use of MDB. The red line shows the best performing parameterization with Mogul constraints, whilst the blue is the best performing with no conformational information. Note that success rates shown here cannot be directly compared with those reported by Kabova et al. (2017), as the data sets used in the current work are those that exhibited low success rates in the parameter tuning work reported by Kabova et al. (2017). 
Table 4

Results obtained from all $D A S H$ runs, expressed as percentage success rate.

$\mathrm{DoF}_{\text {tot }}=$ total number of degrees of freedom; $\mathrm{DoF}_{\text {tor }}=$ number of torsional degrees of freedom; $N_{\text {corr }}=$ number of torsions in crystal structure lying within the constrained range; $N_{\text {incorr }}=$ number of torsions in crystal structure lying outside the constrained range; $N_{\mathrm{NR}}=$ number of torsions for which no Mogul recommendation was made; $N_{\text {filter }}=$ number of torsion angles filtered by Mogul.

\begin{tabular}{|c|c|c|c|c|c|c|c|c|c|c|}
\hline \multirow[b]{2}{*}{ No. } & \multirow[b]{2}{*}{$\mathrm{DoF}_{\text {tot }}$} & \multirow[b]{2}{*}{$\mathrm{DoF}_{\text {tor }}$} & \multirow[b]{2}{*}{$N_{\text {corr }}$} & \multirow[b]{2}{*}{$N_{\text {incorr }}$} & \multirow[b]{2}{*}{$N_{\mathrm{NR}}$} & \multirow[b]{2}{*}{$N_{\text {filter }}$} & \multicolumn{4}{|c|}{ Success rate $(\%)$} \\
\hline & & & & & & & $\begin{array}{l}0.02 / \\
20 / 25\end{array}$ & $\begin{array}{l}0.27 / \\
73 / 56\end{array}$ & Mogul & MDB \\
\hline A7 & 10 & 4 & 3 & 0 & 1 & 0 & 48 & 78 & 98 & 100 \\
\hline A16 & 13 & 7 & 2 & 2 & 0 & 3 & 42 & 74 & 92 & 94 \\
\hline A18 & 14 & 8 & 7 & 0 & 0 & 1 & 4 & 6 & 24 & 32 \\
\hline A19 & 14 & 8 & 4 & 0 & 2 & 2 & 14 & 12 & 18 & 44 \\
\hline A20 & 15 & 9 & 6 & 0 & 3 & 0 & 34 & 88 & 92 & 88 \\
\hline A 21 & 15 & 6 & 5 & 1 & 0 & 0 & 56 & 78 & 96 & 86 \\
\hline A22 & 16 & 10 & 8 & 2 & 0 & 0 & 28 & 74 & 94 & 98 \\
\hline A23 & 16 & 7 & 6 & 0 & 1 & 0 & 54 & 92 & 98 & 94 \\
\hline A24 & 16 & 4 & 2 & 1 & 1 & 0 & 50 & 84 & 44 & 48 \\
\hline A25 & 17 & 11 & 7 & 1 & 2 & 1 & $2 \dagger$ & 24 & 4 & 6 \\
\hline A26 & 17 & 11 & 8 & 2 & 0 & 1 & $1 \dagger$ & 10 & 30 & 2 \\
\hline A28 & 18 & 3 & 2 & 0 & 1 & 0 & 8 & 40 & 54 & 48 \\
\hline A 30 & 18 & 6 & 4 & 0 & 1 & 1 & 34 & 56 & 56 & 20 \\
\hline A31 & 18 & 12 & 6 & 0 & 3 & 3 & 16 & 20 & 16 & 12 \\
\hline A32 & 20 & 8 & 8 & 0 & 0 & 0 & 18 & 54 & 74 & 70 \\
\hline A33 & 20 & 5 & 3 & 1 & 1 & 0 & 14 & 40 & 62 & 84 \\
\hline A34 & 22 & 14 & 12 & 1 & 1 & 0 & 4 & 36 & 60 & 28 \\
\hline A35 & 24 & 6 & 0 & 1 & 1 & 4 & 14 & 48 & 16 & 70 \\
\hline A36 & 24 & 12 & 5 & 5 & 2 & 0 & 46 & 72 & 80 & 98 \\
\hline A37 & 25 & 13 & 7 & 0 & 3 & 3 & 0 & $1 \dagger$ & $0 \ddagger$ & $0.4 \ddagger$ \\
\hline A39 & 28 & 4 & 1 & 3 & 0 & 0 & $1 \dagger$ & 4 & $2 \dagger$ & 4 \\
\hline A 40 & 30 & 12 & 12 & 0 & 0 & 0 & $0.2 \ddagger$ & 4 & $0.2 \ddagger$ & $0.4 \ddagger$ \\
\hline B21 & 10 & 4 & 0 & 0 & 2 & 2 & 44 & 60 & 96 & 96 \\
\hline B27 & 12 & 3 & 3 & 0 & 0 & 0 & 44 & 78 & 100 & 100 \\
\hline B31 & 13 & 7 & 3 & 1 & 3 & 0 & 58 & 50 & 98 & 96 \\
\hline B34 & 14 & 8 & 6 & 0 & 2 & 0 & 50 & 100 & 100 & 100 \\
\hline B35 & 14 & 8 & 8 & 0 & 0 & 0 & 14 & 48 & 100 & 100 \\
\hline B36 & 14 & 8 & 7 & 0 & 0 & 1 & 4 & 12 & 84 & 44 \\
\hline B37 & 14 & 8 & 7 & 0 & 0 & 1 & 12 & 30 & 100 & 100 \\
\hline B38 & 14 & 8 & 7 & 0 & 0 & 1 & 36 & 76 & 100 & 100 \\
\hline B39 & 14 & 8 & 7 & 0 & 1 & 0 & 4 & 14 & 98 & 96 \\
\hline B40 & 14 & 8 & 7 & 0 & 1 & 0 & 8 & 26 & 100 & 96 \\
\hline B42 & 14 & 5 & 1 & 2 & 2 & 0 & 20 & 44 & 42 & 6 \\
\hline B43 & 16 & 7 & 4 & 2 & 1 & 0 & 12 & 32 & 92 & 86 \\
\hline B44 & 16 & 7 & 1 & 0 & 2 & 4 & 8 & 48 & 56 & 66 \\
\hline B45 & 16 & 4 & 3 & 1 & 0 & 0 & 14 & 54 & 56 & 46 \\
\hline B46 & 16 & 4 & 3 & 1 & 0 & 0 & 4 & 70 & 80 & 60 \\
\hline B47 & 18 & 9 & 5 & 1 & 3 & 0 & 14 & 54 & 94 & 98 \\
\hline B48 & 20 & 8 & 5 & 3 & 0 & 0 & $4 \dagger$ & 12 & 4 & 10 \\
\hline B49 & 20 & 14 & 11 & 1 & 2 & 0 & $0 \ddagger$ & $1 \dagger$ & $1 \dagger$ & 14 \\
\hline B50 & 21 & 6 & 3 & 1 & 1 & 1 & $0.2 \ddagger$ & $0 \dagger$ & 10 & 8 \\
\hline B51 & 21 & 6 & 3 & 1 & 1 & 1 & $1 \dagger$ & 6 & 86 & 78 \\
\hline B52 & 24 & 6 & 4 & 0 & 1 & 1 & $9.4 \ddagger$ & 18 & 68 & 56 \\
\hline B53 & 25 & 13 & 7 & 2 & 0 & 4 & 2 & 22 & $0 \dagger$ & 46 \\
\hline B54 & 26 & 14 & 7 & 1 & 0 & 6 & $2 \ddagger$ & $1 \dagger$ & 4 & 8 \\
\hline B55 & 28 & 4 & 0 & 4 & 0 & 0 & 4 & 90 & 78 & 90 \\
\hline B56 & 28 & 10 & 2 & 3 & 0 & 5 & $0 \ddagger$ & $0 \ddagger$ & $0.8 \ddagger$ & 0.4 \\
\hline B57 & 28 & 22 & 19 & 2 & 1 & 0 & $0 \ddagger$ & 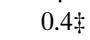 & $0 \ddagger$ & $1 \dagger$ \\
\hline B59 & 33 & 15 & 15 & 0 & 0 & 0 & 0 & 0.4 平 & $1.2 \ddagger$ & $2 \ddagger$ \\
\hline B60 & 42 & 6 & 6 & 0 & 0 & 0 & $0.4 \ddagger$ & $1 \dagger$ & $4.6 \ddagger$ & $5 \ddagger$ \\
\hline B61 & 49 & 43 & 37 & 3 & 3 & 0 & $0 \ddagger$ & $0 \ddagger$ & $0 \ddagger$ & $0 \neq$ \\
\hline
\end{tabular}

\section{Results}

The results are summarized in Table 4, which demonstrates that considerable improvements in SR were observed when the Mogul and MDB approaches outlined above were utilized. The best fit lines from the ELO analysis performed on all the results obtained in this work are shown in Fig. 4.

Table 4 also includes information on how well the Mogulderived distributions described the torsion angles present in the molecules of the crystal structures being solved in this work. Of the 453 variable torsion angles present:

(a) 309 were constrained to ranges that spanned the values observed in the reference crystal structures.

(b) 49 were constrained to ranges which did not span the values observed in the reference crystal structures.

(c) 95 could not be constrained on the basis of their Mogul distributions, but were still available for use by MDB (with the exception of the Mogul-filtered torsions).

\section{Discussion}

The overall benefit of using MDB or Mogul constraints during the SA process is most clearly shown by the ELO analysis (Fig. 4) performed on all the results obtained in this work. The shift to the right of the fitted curves, relative to the conventional $D A S H$ approach using optimized SA parameters, shows the increased probability of solving a crystal structure owing to the inclusion of Mogul-derived information. These gains, which were obtained in combination with $D A S H$ 's optimized SA parameters (Kabova et al., 2017), were also realized when $D A S H$ 's default SA parameters were used [results not shown here; see Kabova (2016) for full details].

Interestingly, the use of torsion angle constraints which did not span the torsion angle values seen in the final crystal structure did not necessarily preclude obtaining a good solution; the simplex minimization employed at the end of the SA ignores the Mogul constraints and gives the possibility that the correct torsion angle values can be recovered. For example, with structure A36, five of the 12 torsion angle constraints did not span the crystal structure values, but the mean absolute angle difference was only $12.5^{\circ}$, and an increase in the SR with both constraints and MDB was still seen. Unsurprisingly, the MDB approach deals better with such cases than the constraint-based approach; an MDB distribution does not explicitly preclude a parameter taking an unlikely value during the SA itself, it merely makes it less likely that it is sampled.

Because of the chemical diversity of structures in the CSD, and the numerous factors that influence their packing into a crystal structure, it is inevitable that novel crystal structures will possess torsion angles that are not well represented in the CSD. Even though there are nearly 900000 crystal structures in the $\mathrm{CSD},{ }^{4}$ some torsion angles are only found in a very small number of structures and so either their MDB influence on the SA is minimal or no valid Mogul-derived constraints can be derived. Table 4 shows, for each structure studied, the number of torsion angles flagged as 'no recommendation' by Mogul, when either the torsion angle of interest is poorly represented in the CSD or the torsion angle distribution is nearly uniform.

\footnotetext{
${ }^{4}$ February 2017 updated CSD v5.38.
} 
Such cases (around $10 \%$ of the total torsion angles of this work) are treated as fully flexible by $D A S H$. In the case of B57 [ritonavir form II, 28 degrees of freedom (DoF)], the complex molecule was reported to have an unexpected conformation in the crystal structure, as a result of a strong hydrogen-bonding network (Bauer et al., 2001). Whilst the use of conformational information did not allow $D A S H$ to solve the structure with the use of its default SA settings, a solution was obtained with the optimized SA parameters using both MBD and Mogulderived constraints, although the latter required the use of 500 SA runs.

When using Mogul-derived torsion angle information, it is important to consider the way in which torsion angles are defined in the input model $Z$-matrices. ${ }^{5}$ If, for example, the input $Z$-matrix contains a torsion angle that is defined using at least one hydrogen atom, then no Mogul distribution is generated and potential information is lost. ${ }^{6}$ Taking B56 (a structure for which no solution was obtained in the absence of torsion angle information) as an example, five of the ten torsion angles in the $Z$-matrix (as automatically generated by $D A S H)$ are described with the use of a hydrogen atom and as such are ineligible for inclusion in the $M o g u l / \mathrm{MDB}$ distributions. This represents a considerable loss of information, but despite this, two correct solutions were found using MDB with $500 \mathrm{SA}$ runs. A simple workaround for this hydrogen-related issue, when using a CIF input model, is to manually re-order atoms in the CIF, such that all the hydrogen atoms appear at the end of the atom list. Future releases of $D A S H$ may address this issue by changing its $Z$-matrix generating code, or by giving the option to include filtered results in a distribution.

The reduction in the SR observed for a small number of compounds (e.g. A37, A40 and B60) must be addressed. In the cases of $\mathrm{A} 40$ and $\mathrm{B} 60$, the DoF in the problem are largely positional and orientational (18 out of 30 for A40, 36 out of 42 for B60), and as such they are not so heavily influenced by the introduction of conformational information. Interestingly, even when the correct conformations of the three independent molecules of A40 are used as input, and held fixed throughout the SA, DASH fails (with the default settings) to solve the structure within $50 \mathrm{SA}$ runs, indicating the extent of the positional/orientational challenge for this structure.

\section{Conclusions}

This work represents a comprehensive study of the effects of including conformational information, derived from the CSD, on SDPD using the $D A S H$ program. The results provide strong evidence that such information should be routinely employed when faced with complex structures; the necessary tools are already in place (the fully automated MDB option is particularly convenient) and there is no significant computa-

\footnotetext{
5 DASH uses a Z-matrix description (Shankland, 2005) of the molecule internally, with flexible torsion angles flagged as variables for optimization by the SA. If a model is input to $D A S H$ as a CIF, MOL, MOL2, RES or PDB, it is automatically converted to a $Z$-matrix.

6 The angle is 'filtered', on the basis that $\mathrm{H}$-atom positions are often fixed geometrically, are 'assumed' or are otherwise unreliable
}

tional overhead involved in its use. It is likely that other GObased approaches to SDPD can benefit from this type of information and the tools provided in the CSDS are extremely valuable in this regard.

\section{Availability and documentation}

Details of DASH's availability can be found at https:/www. ccdc.cam.ac.uk/solutions/csd-materials/components/dash/.

\section{Acknowledgements}

EAK thanks the University of Reading and the Cambridge Crystallographic Data Centre (CCDC) for funding. We thank Mark Spillman and David Edgeley for their help with various computational matters pertaining to the rapid execution of $D A S H$, and Wei Dong for his help in implementing MDB within $D A S H$. We are also grateful to the University of Reading Chemical Analysis Facility for local powder diffraction facilities.

\section{References}

Allen, F. H. (2002). Acta Cryst. B58, 380-388.

Bauer, J., Spanton, S., Henry, R., Quick, J., Dziki, W., Porter, W. \& Morris, J. (2001). Pharm. Res. 18, 859-866.

Bekö, S. L., Urmann, D., Lakatos, A., Glaubitz, C. \& Schmidt, M. U. (2012). Acta Cryst. C68, o144-o148.

Borea, P. A., Gilli, G., Bertolasi, V. \& Ferretti, V. (1987). Mol. Pharmacol. 31, 334-344.

Bortolotti, M., Lonardelli, I. \& Pepponi, G. (2011). Acta Cryst. B67, 357-364.

Boultif, A. \& Louër, D. (1991). J. Appl. Cryst. 24, 987-993.

Bruno, I. J., Cole, J. C., Edgington, P. R., Kessler, M., Macrae, C. F., McCabe, P., Pearson, J. \& Taylor, R. (2002). Acta Cryst. B58, 389397.

Bruno, I. J., Cole, J. C., Kessler, M., Luo, J., Motherwell, W. D. S., Purkis, L. H., Smith, B. R., Taylor, R., Cooper, R. I., Harris, S. E. \& Orpen, A. G. (2004). J. Chem. Inf. Comput. Sci. 44, 2133-2144.

Burley, J. C. (2005). Acta Cryst. B61, 710-716.

Burley, J. C., Streek, J. van de \& Stephens, P. W. (2006). Acta Cryst. E62, o797-0799.

Bushmarinov, I. S., Dmitrienko, A. O., Korlyukov, A. A. \& Antipin, M. Yu. (2012). J. Appl. Cryst. 45, 1187-1197.

Carpy, A., Léger, J.-M. \& Melchiorre, C. (1985). Acta Cryst. C41, 624 627.

CCDC (2015). Solving the Powder Pattern of Verapamil Hydrochloride. https://www.ccdc.cam.ac.uk/support-and-resources/ccdcresources/ Verapamil_DASH.pdf.

ChemAxon (2011). Marvin 5.4.1.1, https://www.chemaxon.com/.

Chernyshev, V. V., Kukushkin, S. Y. \& Velikodny, Y. A. (2010). Acta Cryst. E66, o613.

Chernyshev, V. V., Yatsenko, A. V., Kuvshinov, A. M. \& Shevelev, S. A. (2002). J. Appl. Cryst. 35, 669-673.

Coelho, A. (2003). TOPAS User Manual. Bruker AXS GmbH, Karlsruhe, Germany.

Cole, J. C., Kabova, E. A. \& Shankland, K. (2014). Powder Diffr. 29, S19-S30.

Cox, D. R. \& Snell, E. J. (1989). The Analysis of Binary Data, 2nd ed. London: Chapman and Hall.

David, W. I. F., Shankland, K., Shankland, N. \& Shankland, N. (1998). Chem. Commun. pp. 931-932. 
David, W. I. F., Shankland, K., van de Streek, J., Pidcock, E., Motherwell, W. D. S. \& Cole, J. C. (2006). J. Appl. Cryst. 39, 910915.

DiMaio, F., Terwilliger, T. C., Read, R. J., Wlodawer, A., Oberdorfer, G., Wagner, U., Valkov, E., Alon, A., Fass, D., Axelrod, H. L., Das, D., Vorobiev, S. M., Iwaï, H., Pokkuluri, P. R. \& Baker, D. (2011). Nature, 473, 540-543.

Dinnebier, R. E., Sieger, P., Nar, H., Shankland, K. \& David, W. I. F. (2000). J. Pharm. Sci. 89, 1465-1479.

Donaldson, J. D., Leary, J. R., Ross, S. D., Thomas, M. J. K. \& Smith, C. H. (1981). Acta Cryst. B37, 2245-2248.

Dorokhov, A. V., Chernyshov, D. Y., Burlov, A. S., Garnovskii, A. D., Ivanova, I. S., Pyatova, E. N., Tsivadze, A. Y., Aslanov, L. A. \& Chernyshev, V. V. (2007). Acta Cryst. B63, 402-410.

Fernandes, P., Florence, A., Shankland, K., Karamertzanis, P. G., Hulme, A. T. \& Anandamanoharan, P. (2007a). Acta Cryst. E63, o247-o249.

Fernandes, P., Florence, A. J., Shankland, K., Karamertzanis, P. G., Hulme, A. T. \& Anandamanoharan, R. P. (2007b). Acta Cryst. E63, o202-o204.

Fernandes, P., Shankland, K., Florence, A. J., Shankland, N. \& Johnston, A. (2007). J. Pharm. Sci. 96, 1192-1202.

Florence, A. J., Baumgartner, B., Weston, C., Shankland, N., Kennedy, A. R., Shankland, K. \& David, W. I. F. (2003). J. Pharm. Sci. 92, 1930-1938.

Florence, A. J., Shankland, K., Gelbrich, T., Hursthouse, M. B., Shankland, N., Johnston, A., Fernandes, P. \& Leech, C. K. (2008). CrystEngComm, 10, 26-28.

Florence, A. J., Shankland, N., Shankland, K., David, W. I. F., Pidcock, E., Xu, X., Johnston, A., Kennedy, A. R., Cox, P. J., Evans, J. S. O., Steele, G., Cosgrove, S. D. \& Frampton, C. S. (2005). J. Appl. Cryst. 38, 249-259.

Freer, A. A., Bunyan, J. M., Shankland, N. \& Sheen, D. B. (1993). Acta Cryst. C49, 1378-1380.

Gadret, M., Goursolle, M., Leger, J. M., Colleter, J. C. \& Carpy, A. (1976). Acta Cryst. B32, 2757-2761.

Griffin, T. A. N., Shankland, K., van de Streek, J. \& Cole, J. (2009). J. Appl. Cryst. 42, 360-361.

Groom, C. R., Bruno, I. J., Lightfoot, M. P. \& Ward, S. C. (2016). Acta Cryst. B72, 171-179.

Helmholdt, R. B., Peschar, R. \& Schenk, H. (2002). Acta Cryst. B58, 134-139.

Ivashevskaya, S. N., van de Streek, J., Djanhan, J. E., Brüning, J., Alig, E., Bolte, M., Schmidt, M. U., Blaschka, P., Höffken, H. W. \& Erk, P. (2009). Acta Cryst. B65, 212-222.

Johnston, A., Florence, A. J., Shankland, K., Markvardsen, A., Shankland, N., Steele, G. \& Cosgrove, S. D. (2004). Acta Cryst. E60, o1751-o1753.
Kabova, E. A. (2016). PhD thesis, University of Reading, UK.

Kabova, E. A., Cole, J. C., Korb, O., López-Ibáñez, M., Williams, A. C. \& Shankland, K. (2017). J. Appl. Cryst. 50, https://doi.org/10.1107/ S1600576717012602.

Kennedy, A. R., Hughes, M. P., Monaghan, M. L., Staunton, E., Teat, S. J. \& Smith, W. E. (2001). J. Chem. Soc. Dalton Trans. pp. 21992205.

Kojicprodic, B., Ruzictoros, Z., Sunjic, V., Decorte, E. \& Moimas, F. (1984). Helv. Chim. Acta, 67, 916-926.

Lefebvre, J., Willart, J.-F., Caron, V., Lefort, R., Affouard, F. \& Danède, F. (2005). Acta Cryst. B61, 455-463.

Llinàs, A., Fábián, L., Burley, J. C., Streek, J. van de \& Goodman, J. M. (2006). Acta Cryst. E62, o4196-04199.

Maccaroni, E., Malpezzi, L. \& Masciocchi, N. (2010). Acta Cryst. E66, o2511.

Macrae, C. F., Bruno, I. J., Chisholm, J. A., Edgington, P. R., McCabe, P., Pidcock, E., Rodriguez-Monge, L., Taylor, R., van de Streek, J. \& Wood, P. A. (2008). J. Appl. Cryst. 41, 466-470.

Majumder, M., Buckton, G., Rawlinson-Malone, C. F., Williams, A. C., Spillman, M. J., Pidcock, E. \& Shankland, K. (2013). CrystEngComm, 15, 4041-4044.

Middleton, D. A., Peng, X., Saunders, D., Shankland, K., David, W. I. F. \& Markvardsen, A. J. (2002). Chem. Commun. pp. 1976-1977.

Minitab (2010). Minitab 17 Statistical Software, http://www.minitab. com/en-us/.

Nishibori, E., Ogura, T., Aoyagi, S. \& Sakata, M. (2008). J. Appl. Cryst. 41, 292-301.

Noguchi, S., Miura, K., Fujiki, S., Iwao, Y. \& Itai, S. (2012). Acta Cryst. C68, o41-044.

Nowell, H., Attfield, J. P., Cole, J. C., Cox, P. J., Shankland, K., Maginn, S. J. \& Motherwell, W. D. S. (2002). New J. Chem. 26, 469472.

Rukiah, M., Lefebvre, J., Hernandez, O., van Beek, W. \& Serpelloni, M. (2004). J. Appl. Cryst. 37, 766-772.

Scapin, G. (2013). Acta Cryst. D69, 2266-2275.

Shankland, K. (2005). IUCr Commission on Crystallographic Computing Newsletter, No. 5, pp. 92-102.

Shankland, N., David, W. I. F., Shankland, K., Kennedy, A. R., Frampton, C. S. \& Florence, A. J. (2001). Chem. Commun. pp. 22042205.

Shin, H. S., Song, H., Kim, E. \& Chung, K. B. (1995). Bull. Korean Chem. Soc. 16, 912-915.

Sorrenti, M., Catenacci, L., Cruickshank, D. L. \& Caira, M. R. (2013). J. Pharm. Sci. 102, 3596-3603.

Streek, J. van de, Brüning, J., Ivashevskaya, S. N., Ermrich, M., Paulus, E. F., Bolte, M. \& Schmidt, M. U. (2009). Acta Cryst. B65, 200-211.

Yatsenko, A. V., Chernyshev, V. V., Paseshnichenko, K. A. \& Schenk, H. (2001). Acta Cryst. C57, 295-297. 